\title{
The Contributions of TQM and Six SIGMA in the Organizations to Achieve the Success in Terms of Quality
}

\author{
Rallabandi Srinivasu \\ Professor \& Director -PG Studies \\ St. Mary's Group of Institutions \\ Hyderabad, India -500070 \\ Vuda Sreenivasarao \\ Professor \& Head CSE, IT Dept \\ St.Mary's College of Engg. \& Technology \\ Hyderabad, India-500070
}

\author{
G. Satyanarayana Reddy \\ Professor \& HOD-MBA \\ CMR College of Information Technology \\ Hyderabad, India -500070 \\ Srikanth Reddy Rikkula \\ Associate Professor, MCA Dept \\ St.Mary's College of Engg. \& Technology \\ Hyderabad, India -500070
}

\begin{abstract}
The objective of this paper is to contribute a clear understanding of TQM \& SIX SIGMA are helpful to the organizations to achieve the success in terms of quality. This paper contains the approaches of SIX SIGMA are DMAIC \& DMADV. The main aim of this paper is to look at TQM \& SIX SIGMA history, definition, importance and the contribution in an Industry and explains the strengths, differences and weaknesses/deficiencies of TQM \& SIX SIGMA and also discussed their distinctive characteristics and similarities.
\end{abstract}

Key words: Total Quality Management (TQM), TQM implementation, SIX SIGMA, DMAIC, DMADV and Quality

\section{INTRODUCTION}

The concept of TQM has dominated the management scene for some decades. Many organisations all over the world have tried to use TQM to achieve increased competitiveness and improved financial results. Some organisations have succeeded. For instance, quality award recipients show better financial results than comparable 'average companies'; see Hendricks and Singhal (1997) and Eriksson and Hansson (2003). However, without doubt, many organisations have also failed; see e.g., discussions in Allen and Kilmann (2001), Brah et al. (2002) and Cao et al. (2000). Although there are several reasons for these mixed results, the failures have tarnished the TQM star and have intensified the search for new and efficient means of navigating the increasing competitiveness of a borderless world. Six Sigma and other concepts, have grown in popularity and many organisations have shifted their strategies and practices towards these concepts. That view is supported by Pande et al. (2000), who assert that "TQM is less visible now than in the early 1990s due to problems including lack of integration, leadership apathy, a fuzzy concept, unclear quality goals and a failure to break down internal barriers" and conclude that Six Sigma can overcome these deficiencies, stating that Six Sigma's expansion heralds a 'rebirth' of the quality movement. Furthermore, Harry (2000) claims that "Six Sigma represents a new holistic, multidimensional systems approach to quality that replaces the 'form, fit and function' specification of the past" and the Financial Times wrote in October 1997 that "Six Sigma is a program aimed at the near elimination of defects from every product, process, and transaction". In the list of books at ASQ Quality Press, probably the largest book store in the world on quality literature, we found 73 books with Six Sigma included in the title (August 2005) but just seven with TQM. On the other hand, USA Today wrote on July 21, 1998:

"Today, depending on whom you listen to, Six Sigma is either a revolution slashing trillions of dollars from corporate inefficiency, or it is the most maddening management fad yet devised to keep front-line workers too busy collecting data to do their jobs."

Whatever the truth is, it seems important to reflect on the reasons for this development, and try to dissect the TQM and Six Sigma concepts and analyze their composition. What is true and what is not? Are TQM and Six Sigma in fact two sides of the same coin - two versions of the same dish? We will scrutinize the two concepts, compare them and present some reflections related to this issue.

\section{TOTAL QUALITY MANAGEMENT (TQM):}

TQM is a systems approach to management that aims to enhance value to customer by designing and continually improving organizational processes and systems. It provides a new vision for management leadership. It places customers as principal focal point and redefines quality as customer satisfaction. TQM relies on fact-based decision-making. TQM is a broad-based approach used by world class companies to achieve organizational excellence, the highest weighted category of all the quality and excellence awards (Oakland, 2001). Most of the researchers agree that TQM is a useful philosophy for management if properly planned and implemented (Black and Porter, 1996; Flynn and Saladin, 2006). It has been proposed that if TQM is used properly and fully integrated into the business, this approach will help any organization deliver its goals, targets and strategy (Oakland, 2001). According to Lundquist (1995), TQM implementation is based on three core elements:

- The TQM philosophy that comprises a set of TQM principles; 
- The organizational culture - the present and desired state of culture that will be reached when the TQM philosophy is realized; and

- The implementation strategy - the approach to realizing the philosophy that will specifically include the activities to identify and offset TQM implementation barriers.

The competing value framework (CVF) proposed and tested by Denison and Spreitzer (1991) has been selected to identify types of organizational culture and explore underlying dynamics of culture in terms of TQM practices being supported by type of culture.

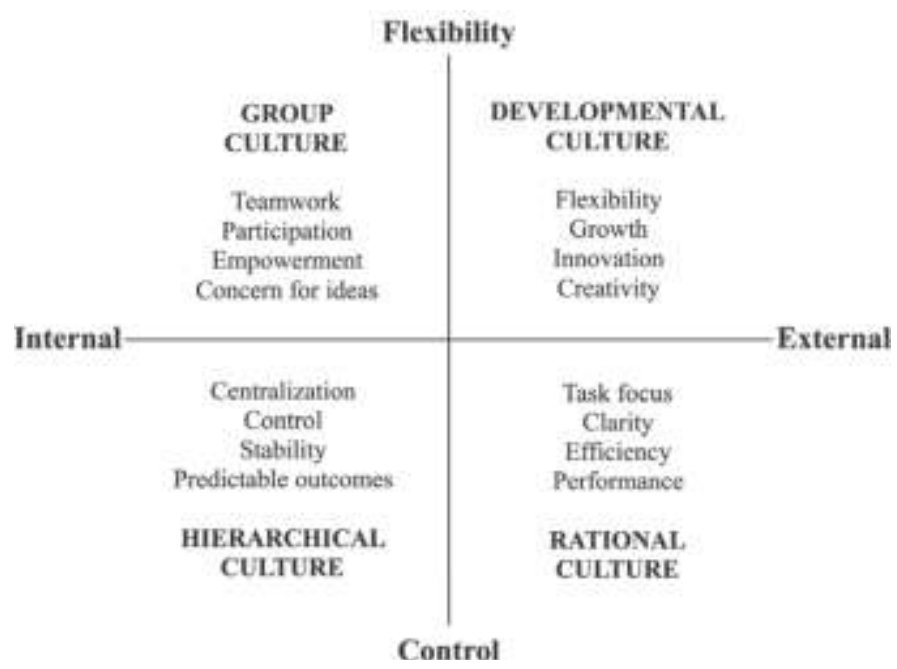

Figure1.The competing values framework of organizational culture (adapted from Denison and Spreitzer, 1991)

Five empirical studies have been identified to derive significant TQM principles for implementation to achieve performance excellence: (Ho and Fung, 1994; Mann and Kehoe, 1994; Powell, 1995; Black and Porter, 1996; Choi and Eboch, 1998). Based on this literature a total of 48 significant TQM practices were identified and categorized into eight major TQM principles:

- Top management commitment

- Quality planning

- Customer and market focus

- Employee focus

- Information management

- Process Control

- Supplier management

- Quality culture

TQM is for achieving excellence (Jabnoun and Sedrani, 2005) and TQM is for continuous quest for excellence (Lakhe and Mohanty, 1994). TQM can be defined as holistic management philosophy aimed at continuous improvement in all functions of an organization to deliver goods and services in line with customers' needs or requirements (Demirbag et al., 2006).

Feigenbaum illustrates that Total Quality Management is the consequent further development of Statistical Process Control and Total Quality Control (Feigenbaum, 1991) (see Figure 2). The method of improving the quality by extracting faulty components became more cost-effective with the introduction of statistical measures which can mainly be traced back to Shewart who introduced the difference between chance-cause and assignable-cause origins of variations and developed the quality control chart (Shewhart, 1980).

TQM is defined by Feigenbaum as both a philosophy and a set of guiding principles that represent the foundation of a continuously improving organization. It is the application of quantitative methods and involvement of people to improve all the processes within an organization and to exceed customer needs.

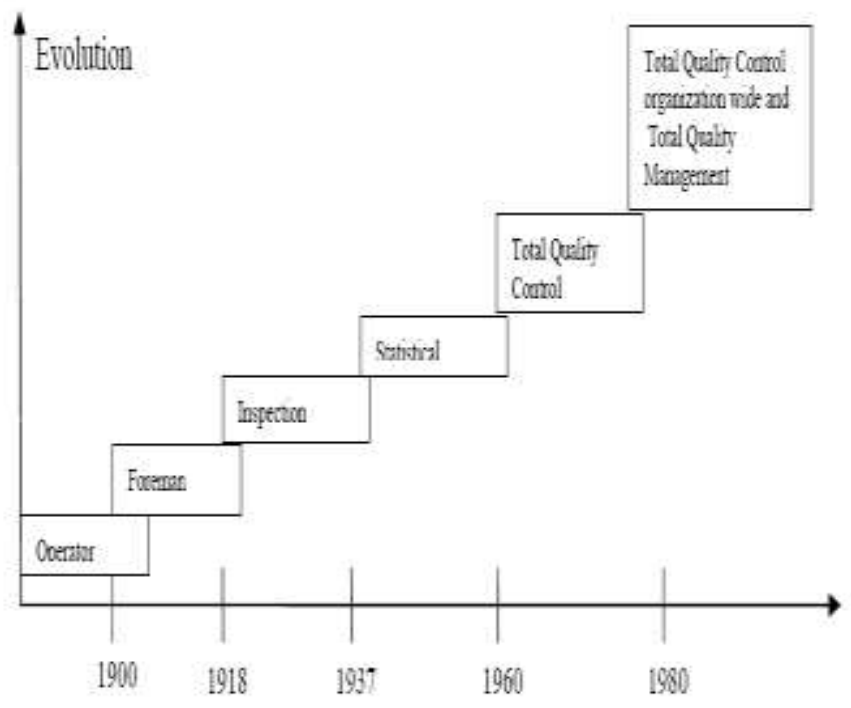

Figure 2: Historical evolution of quality methods (Feigenbaum, 1991)

Deming advocated that all managers need to have what he called a System of Profound Knowledge (SPK) (Deming, 1986). After being invited to Japan, Deming introduced SPK in the late 1940s and early 1950s where he also visited Toyota and taught his 14 key principles for management (Deming, 1986). It needs to be noted that the established problem solving process called PDCA cycle can also be traced back to Shewart and Deming.

The quality movement has a long history. Often, its development is described in terms of a four phase model consisting of quality inspection, quality control, quality assurance and (total) Quality Management; see Bergman and Klefsjö (2003), Dale (1999) and Kanji and Ascher (1993). However other, maybe more realistic, descriptions of the development can also be found. One of these is using two schools of thought, called the Deterministic School of Thought and the Continuous Improvement School of Thought; see Kroslid (1999). The origin of the name TQM is, by the way, disputed; discussions can be found in Martinez-Lorente et al. (1998) and Bergman and Klefsjö (2003). 
In recent years some definitions with a system emphasis have been suggested. These are based on a kernel of core values that seems to have converged (Sila and Ebrahimpour, 2002). One of these definitions is from Hellsten and Klefsjö (2000), who define TQM "as a continuously evolving management system consisting of values, methodologies and tools, the aim of which is to increase external and internal customer satisfaction with a reduced amount of resources", see Figure 3. They argue that the methodologies (or "ways to work consisting of a sequence of activities") and tools (that is, "more concrete diagrams or matrices, sometimes with a statistical base") should consequently and continuously be chosen to support the values to be part of the culture. The three units together form in that way the whole.

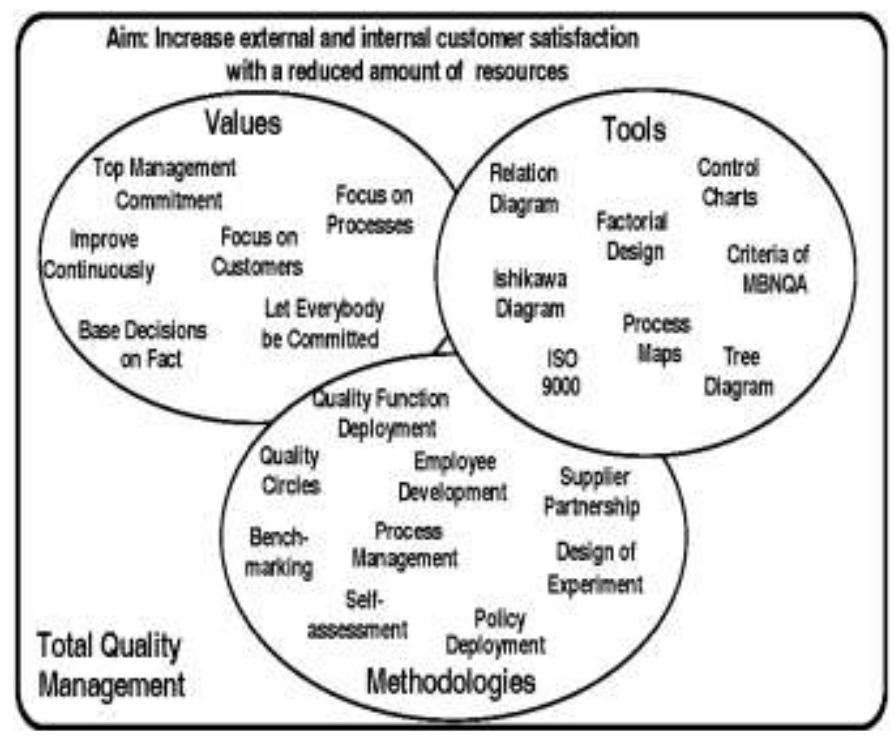

Figure 3: Total Quality Management (TQM) seen as a management system consisting of values, methodologies and tools. The methodologies and tools in the figure are just examples and not a complete list

Although the system view is not always as clear as in Hellsten and Klefsjö (2000), many definitions of TQM of today contain the ingredient values (sometimes called core values, principles or cornerstones as well) and ways to work (also called methods, methodologies or techniques). TQM can, in most descriptions, be characterized by a number of values, illustrating how we should act in our profession. These focus on the six values mentioned in Figure 3 i.e., on continuous improvements, fact based decisions, participation of all the staff, process focus and, last but not least, a customer perspective in what we do.

TQM is also seen as permeating the entire organization. Another characteristic of TQM is that it encompasses all the organization, and preferably suppliers and customers as well. Tobin (1990) has stated that TQM is a totally integrated programme for gaining competitive advantages by continuously improving every facet of organizational culture. Around 1980 Robert Galvin, at that time $\mathrm{CEO}$ at Motorola, realized the importance of working systematically with variance reduction as the Japanese had done for a prolonged period (Bergman and Klefsjö, 2003). Together with Bill Smith, Mikel Harry and
Richard Schroeder, he created an improvement program that was given the name Six Sigma. According to Basu (2004), Bill Smith came up with the idea of "inserting hard-nosed statistics into the blurred philosophy of quality". The program was inspired by Japanese work, but also strongly influenced by Juran's thoughts. Due to Six Sigma, Motorola managed to reduce their costs and variation in many processes and were an inaugural winner of America's Malcolm Baldrige National Quality Award in 1988. They reported a profit from the program of USD 700 million for 1991 alone (Bergman and Klefsjö, 2003). Another example is the Volvo Car Corporation in Sweden who claim that their Six Sigma programme has contributed with more than 55 million Euro to the bottom line between 2000 and 2002 (Magnusson et al., 2003).

\section{SIX SIGMA:}

Six Sigma was started in Motorola by engineer Bill Smith in the late 1980s in order to address the company's chronic problems of meeting customer expectations in a cost-effective manner. Within improvement projects quality problems were systematically analyzed at the front end of the process and continued throughout the manufacturing process using four phases (Measure, Analyse, Improve, Control). Jack Welch, the CEO of GE applied this program across all of GE integrating training of Six Sigma into the promotion structure. GE added an extra phase to define and manage improvement projects. Therefore the Six Sigma methodology offers an organizational structure where certified experts (Master black belts, black belts and green belts) lead the improvement projects. According to Kedar et al. Six Sigma gives clear change of structure and is much more orientated on fast and tangible results in comparison with TQM, TPM, and Lean (Kedar et al., 2008). Hereby the main focus lies in the elimination of variation in processes in order to achieve immediate cost savings. Näslund concludes that Six Sigma is a further development of TQM. He found similarities in the problem solving process (Deming wheel and DMAIC cycle), the importance of top management commitment, the necessary employee involvement, and in statistical methods (Näslund, 2008).

\subsection{SIX SIGMA OBJECTIVE:}

The primary objective of the Six Sigma methodology is the implementation of a measurement based strategy, which focuses on process and sub-processes improvement through the application of Six Sigma best practice such as DMAIC and DMADV. The Six Sigma DMAIC (Define, Measure, Analyze, Improve, Control) method is applied for improving existing processes and looking for incremental improvement. The Six Sigma DMADV (Define, Measure, Analyze, Design, Verify) is applied for developing new processes or products at Six Sigma quality levels. It can also be employed if a current process requires more than just incremental improvement. According to the Six Sigma Academy, companies save approximately $\$ 230,000$ per project by applying Six Sigma concept. General Electric, for example, one of the most successful companies implementing Six Sigma, has estimated benefits on the order of $\$ 10$ billion during the first five years of implementation. GE first began Six Sigma in 1995 after Motorola and Allied Signal 
blazed the Six Sigma trail. Since them, companies around the world have discovered the far reaching benefits of Six Sigma. The implementation of Six Sigma follows a strict protocol. First, projects are selected starting with those that are thought to have the highest organizational priority. For many years the process of Six Sigma implementation followed a five-step process referred to as DMAIC. However, there is a new eight-step Six Sigma Breakthrough Process that many organizations are using to rework quality issues. The eight steps include: Recognize, Define, Measure, Analyze, Improve, Control, Standardize, and Integrate.

The Six Sigma of today speaks the language of management: bottom-line results. It institutionalizes a rigorous, disciplined, fact-based way to deliver more money to the bottom line through process improvement and process design projectsselected by the top leadership and led by high potentials trained as Black Belts or Master Black Belts in Six Sigma - that aim to create near-perfect processes, products, and services all aligned to delivering what the customer wants. In successful implementations, the majority of Six Sigma projects are selected for measurable bottom-line or customer impact that is completed within two to six months. The projects deliver through the application of a well-defined set of statistical tools and process improvement techniques by well-trained people in an organization that has made it clear that Six Sigma is a career accelerator.

Ours is an increasingly complex world - or at the least its inherent complexity is made ever more apparent by burgeoning woes that span societal, environmental, technological and economic realms. That is precisely where Six Sigma comes into play: rapid development and deployment of breakthrough solutions in areas of critical need. Many of the methods of Six Sigma will be familiar to the reader, for they are statistical ones long in use or management and planning ones that are in vogue in environments where teamwork, continuous improvement, and breakthrough thinking are valued.

If this is so, then the question begs: "what is new about Six Sigma?" It is the team-oriented organization and notorious bottom-line focus - and some very high profile success stories that have put it in the spotlight. As such, it is of value to know the basic vocabulary and approach of Six Sigma. While use of the term bottom-line brings to mind the most common one, that is, financial results, business has more-and-more begun to recognize multiple bottom-lines including, for example, ones related to society and the natural environment and the BEST Business Excellence Model (Edgeman 2000, 2002a, 2003) adds a technological bottom-line.

\subsection{SIX SIGMA'S DMAIC AND DMADV APPROACHES:}

Like many organizations, those making use of Six Sigma typically have exceptional human capital. Not all organizations peopled by exceptional personnel achieve excellent results, however. What sets Six Sigma organizations apart from others is application of a structured knowledge-acquisition / problemsolving approach known as DMAIC, an acronym that represents "Define-Measure-Analyze-Improve-Control" or its design methodology for new processes - Design for Six Sigma with its associated Define-Measure-Analyze-Design-Verify (DMADV) approach that creates synergy between genius and quality that is characterized by superior ideas proved to be so by superior results in areas of strategic import. Included among those results in Six Sigma organizations is superior financial performance. That this is central to Six Sigma can be verified by examination of quality within the context of the value proposition wherein Six Sigma regards quality as a state in which value entitlement is realized for the customer and provider in all aspects of the business relationship and is highest when costs are at their absolute lowest for producer and consumer alike. Six Sigma provides maximum value to organizations in the form of increased profits and maximum value to the customer in the forms of high product and service quality at the lowest possible cost (Harry and Schroeder, 2000).

Effectively, DMAIC is a highly data-driven, fact-based application of the scientific method of inquiry that emphasizes discernment and implementation of the so-called "voice of the customer" (VOC) as related to processes, products and services that create value both for the producer and the consumer. Given Six Sigma's core value for data-driven decision-making, it should not surprise the reader to learn that exceptionally effective methods for discerning the VOC exist. This critical effort is key to DMAIC's first phase - the Define phase - with other steps including problem definition and development of a charter for the Six Sigma team. Applied systematically and strategically DMAIC produces bottom-line results superior to those achieved through other approaches.

In process improvement applications of Six Sigma the focus is trained on identification and implementation of targeted solutions. In this context DMAIC is applied as follows:

- Define the problem and customer requirements.

- Measure defect rates and document the process in its current incarnation.

- Analyze process data and determine the capability of the process.

- Improve the process and remove defect causes.

- Control process performance and ensure that defects do not recur.

In contrast, applications of Six Sigma that focus on the design or redesign or products and services and their enabling processes so that from the beginning customer needs and expectations are fulfilled are known as Design for Six Sigma (DFSS). The focal aim of DFSS is to create designs that are resource efficient, capable of exceptionally high yields, and are robust to process variations. This aim produces a recasting of DMAIC that can be aptly characterized as Define-Measure-Analyze-Design-Verify (DMADV) and described as follows.

- Define customer requirements and goals for the process, product or service.

- Measure and match performance to customer requirements.

- Analyze and assess the design for the process, product or service.

- Design and implement the array of new processes required for the new process, product or service.

- Verify results and maintain performance.

Harry (2000) claims that "Six Sigma represents a new holistic, multidimensional systems approach to quality that replaces the 'form, fit and function' specification of the past" and the Financial Times wrote in October 1997 that "Six Sigma is a 
program aimed at the near elimination of defects from every product, process, and transaction".

Tools and techniques used in various of these phases include process maps, quality function deployment, Pareto charts, scatter diagrams, affinity diagrams, brainstorming, the nominal group technique, as well as more substantial quantitative approaches such as correlation analysis, design of experiments, and regression analysis (Pyzdek, 2001). In applying these tools focus is fanatically trained on knowledge acquisition, particularly as relates to optimal fulfillment of the VOC - that is, on win-win solutions that benefit both the producer and consumer.

The name Six Sigma refers to the capability of the process to deliver units within the set limits. The Greek letter $\sigma$ or 'sigma', corresponding to our ' $\mathrm{s}$ ', is a notation of variation in the sense of standard deviation. For a stable process the distance from the process mean to the nearest tolerance limit should, according to the Six Sigma approach, be at least six times the standard deviation $\sigma$ of the process output. However, the process mean is also allowed to vary somewhat over time. If the process mean varies at most $1.5 \sigma$ from the

target value, then on average at most 3.4 Defectives Per Million Opportunities (DPMO) will occur if the output is normally distributed; see Table 1. A $6 \sigma$-process corresponds in a sense to a value of 2.0 of the capability index $C p$ or 1.5 for $C p k$ when allowing for a $1.5 \sigma \mathrm{drift}$ in process mean (see Table 1 ).

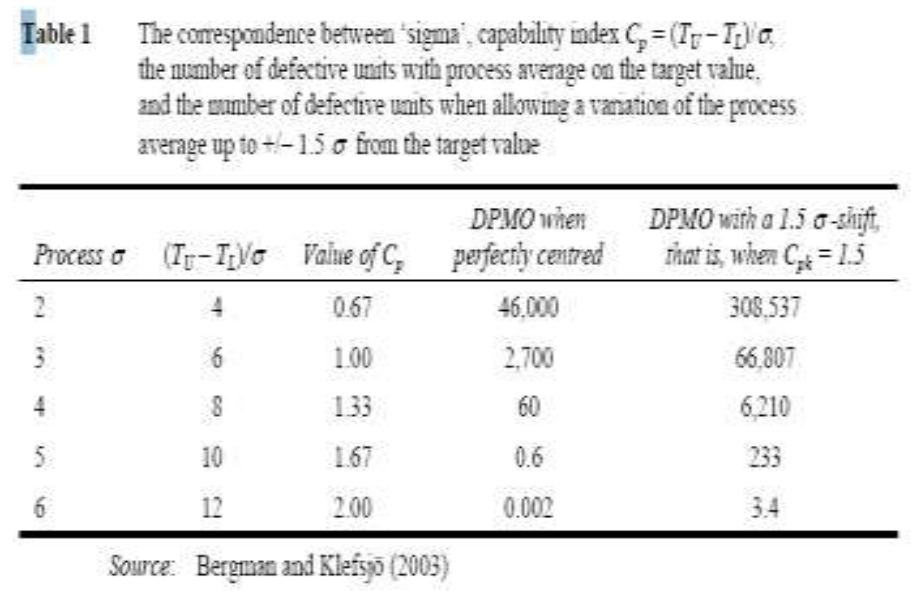

The TQM concept has been blamed for being vague - let us therefore briefly look at some definitions found in recent literature of Six Sigma. Do we really have a consistent picture of what it means or is the definition of Six Sigma also vague?

"Six Sigma is a business improvement approach that seeks to find and eliminate causes of mistakes or defects in business processes by focusing on process outputs that are of critical importance to customers." (Snee, 2004)

"A Six Sigma initiative is designed to change the culture in an organization by way of breakthrough improvement in all aspects of the business." (Breyfogle et al., 2001)

Herold et al. (2003) add a list of 'some common descriptions' to our list with formulations such as “... a statistical way of measuring quality control”, “... a high-performance, data-driven approach to analysing the root causes of business problems and solving them", “... first and foremost a philosophical approach that demands the effective use of data to analyse business issues" and "... attempts to insert the science of hard-nosed statistics into the foggy philosophy of quality". To sum up, there is, as Goodman and Theuerkauf (2005) say, certainly no common definition of Six Sigma.

An important part of Six Sigma is the DMAIC procedure: Define - Measure - Analyse - Improve - Control. Conceptually DMAIC is a highly structured and rigorous problem-solving approach, but one that offers a good deal of freedom within each step so long as the Six Sigma team holds true to the intent of each step and the goals of each step are accomplished. In many aspects, however, DMAIC is simply a more polished version of a more 'ancient' and very familiar improvement cycle: Plan Do - Study - Act or PDSA. This PDSA cycle, which was popularised by Deming, especially with his presentation in Japan in 1950, was adopted by Deming from an earlier version developed by his mentor Walter A. Shewhart.

However, there have been many problems inside organizations that have created obstacles to improving performance and confronted by fierce overseas competitors. There appears to be a need for Total Quality Management (TQM) that benefits from well-managed organization. TQM principles have been developed over many years by Quality practitioners, the core concepts of its approach were derived from three core principles; (1) Achieving customer satisfaction, (2) Striving for continuous improvement, and (3) encouraging the full invol vement of the entire workforce.

The terms of "total quality" started to become popular in the USA in the 1970s, referring to various elements of Japanese solutions for quality, that helped Japanese economy rebuild after the second world war. The foundations of TQM were established in Japan in 1950s, with great involvement of American statisticians W. Edwards Deming and Joseph M. Juran. Not going deep into details - TQM proved to be very successful management approach and set of tools and practices. It changed the perception of quality from post production inspection to aspect of each single activity within the organization. Some particular practices derived from TQM proved to be foundation of various organizations' success. Toyota's success is heavily based on Toyota Production System, which later evolved into Lean Manufacturing (Sangeeta Sahney, Banwet D.K \& Karunes S., 2004) and became a kind of standard for production companies. One of Motorola's ways to get through 1980's product quality crisis was introduction of Six Sigma program - a set of practices based on statistical metrics that helped to reduce significantly the number of defects (Surya Rao. U, and Pal Pandi A. 2006). Six Sigma was later on adapted to any kind of business process improvements, giving the most significant example of it's efficiency in General Electric (Surya Rao, U., Pal Pandi A. and Jeyathilagar .D, 2007) .

The foundation of the Six Sigma program is statistics; sigma stands for standard deviations from the mean of a data set in other words a measure of variation, while Six Sigma stands for six standard deviations from the mean. When a process reaches the six sigma level that process will be running close to perfection, producing a mere 3.4 defects per million. By using statistical and analytical tools firms can reduce the amount of variation in a process by removing the causes of variation therefore increasing the output quality of the process.

Some examples of companies that have successfully implemented a Six Sigma program are: 
- GE boasts gains of $\$ 2$ billion to the bottom line in 1999 and \$2.4 billion in 2001 because of Six Sigma.

- Motorola saved $\$ 15$ billion in the first 10 years of Six Sigma implementation

- $\quad$ Dupont realized more than $\$ 1.6$ billion in cost savings the first four years of Six Sigma.

- Many other companies and even municipalities have had similar success by implementing Six Sigma (Greg Brue and Rod Howes, 2006).

Implementing Six Sigma requires having the "right people in the right seats" to be Successful (Jim Collins, 2001)

\section{CONCLUSION}

This paper explores the contribution of TQM and SIX SIGMA in the organizations. TQM has been used successfully in variety of organizations, including manufacturing and service organizations. Firms that want to implement TQM effectively must have patience. It is widely accepted that TQM takes a long time to implement as it requires major organizational changes in culture and employee mindset. To get the benefits from TQM, one must be patient. It improves performance in the long-haul. Finally, we believe that TQM has still a long way to go. Recent surveys show that about 30 percent of manufacturing plants in United States have widely embraced TQM (Tanincez, 1997). Investigations show that organizations that have implemented TQM successfully have better financial results than the average company'. Well - known investigations of this issue include Hendricks and Singhal (1997) and Eriksson and Hansson (2003), who both, over two time periods, compare financial indicators of quality award recipients with comparable ' average companies '. Teambuilding is an essential element of Six Sigma. One of the most basic tents of Six Sigma is constant improvement. The Six Sigma Quality Control Program mandates training in all aspects of organizational processes. Any business processes that incorporate Six Sigma must be refined and this refining process requires training. One of the greatest advantages that the Six Sigma Quality Control Program offers organizations is the reported return on investment. Finally, Six Sigma can introduce an increased aptitude for change. The purpose of this paper has been to better understand what Six Sigma is as described by a rapidly developing body of literature. Six Sigma is generally described as a metric, a mindset, and methodology for strategic management and process improvement. And how the Six Sigma and TQM are helpful in an industry. Six Sigma provides an effective mechanism to focus on customer requirements, through improvement of process quality. The Six Sigma Approach is customer-driven. For a business or a manufacturing process, the Sigma Capability is a metric that indicates how well the process is being performed. The Six Sigma Approach is also data-driven. It focuses on reducing process variation, centering the process and on optimizing the process. TQM is an approach to improving the competitiveness, effectiveness and flexibility of an organization for the benefit of all stakeholders. It a way of planning, organizing and understanding each activity, and of removing all the wasted effort that is routinely spent in organizations.

\section{REFERENCES}

[1] Allen, R.S. and Kilmann, R.H. (2001) 'The role of the award system for a Total Quality Management based strategy', Journal of Organizational Change, Vol. 14, No. 2, pp.110-131.
[2] Basu, R. (2004) 'Six Sigma to operational excellence: role of tools and techniques', International Journal of Six Sigma and Competitive Advantage, Vol. 1, No. 1, pp.44-64.

[3] Bergman, B. and Klefsjö, B. (2003) Quality from Customer Needs to Customer Satisfaction,

[4] Black, S. and Porter, L. (1996) 'identification of critical factors of TQM', Decision Sciences, Vol. 27, No. 1, pp. 121

[5] Brah, S.A., Tee, S.S.L. and Madhu, R.B. (2002) 'Relationship between TQM and performance of Singapore companies', International Journal of Quality and Reliability Management, Vol. 19, No. 4, pp.356-379.

[6] Breyfogle III, F.W., Cupello, J.M. and Meadows, B. (2001) Managing Six Sigma, John Wiley \& Sons, New York.

[7] Cao, G., Clarke, S. and Lehaney, B. (2000) 'A systematic view of organisational change and TQM', The TQM Magazine, Vol. 12, No. 3, pp.186-193. Six Sigma and Total Quality Management: different day, same soup?

[8] Dale, B.G. (1999) Managing Quality, Blackwell Publishers, Oxford.

[9] DEMING, W. E. (1986) Out of the crisis: quality, productivity and competitive position, Cambridge University Press.

[10] Demirbag, M., Tatoglu, E., Tekinkus, M. \& Zain, S. (2006), "An analysis of the relationship between TQM implementation and Organizational Performance", Journal of Manufacturing Technology Management, Vol.17

[11] Edgeman, R.L., "BEST Business Excellence: An Expanded View", Measuring Business Excellence, Vol. 4, No. 4, pp. 1517,2000

[12] Edgeman, R.L., "BEST Business Excellence: Ethical Resolution of Business Excellence \& Sustainable Development" in Business Ethics in Higher Education, Technikon Free State Studies in Higher Education, No. 4, 24-37. Bloemfontein, South Africa, L.O.K. Lategan \& Piet le Roux, Editors, 2002a

[13] Edgeman, R.L., "Synergy for Human Heart: Excellence and Sustainability at the Crossroads", AI and Society, Vol. 17, No. 2, pp. 200-202, July 2003.

[14] Eriksson, H. and Hansson, J. (2003) 'The impact of TQM on financial performance', Measuring Business Excellence, Vol. 7, No. 1, pp.36-50.

[15] FEIGENBAUM, A. V. (1991) Total quality control, New York, McGraw-Hill. management. Work study, Vol. 43.

[16] Flynn, B.B. and Saladin, B. 2006, "Relevance of Baldrige constructs in an international context: A study of national culture", Journal of Operations Management, vol. 24, no. 5, pp. 583

[17] Goodman, J. and Theuerkauf, J. (2005) 'What's wrong with Six Sigma?', Quality Progress, Vol. 38, January, pp.37-42.

[18] Greg Brue and Rod Howes. "Six Sigma The McGraw-Hill 36-Hour Course," 2006.

[19] Harry, M. and Shroeder, R., Six Sigma: The Breakthrough Management Strategy Revolutionizing the World's Top Corporations, New York, Currency-Doubleday, 2000. 
[20] Hellsten, U. and Klefsjö, B. (2000) 'TQM as a management system consisting of values methodologies and tools', The TQM Magazine, Vol. 12, No. 4, pp.238-244.

[21] Hendricks, K.B. and Singhal, V.R. (1997) 'Does implementing an effective TQM programme actually improve operating performance?', Management Science, Vol. 43, No. 9, pp.1258-1274.

[22] Herold III, F.C., Carden, P. and Stephens, K. (2003) 'Six Sigma', Six Sigma and Related Studies in the Quality Disciplines. The Best on Quality Book Series of the International Academy for Quality, Vol. 14, Chapter 2, pp.15-34.

[23] Jim Collins. "Good to Great," 2001, pg. 41.

[24] Kanji, G.K. and Ascher, M. (1993) Advances in Total Quality Management - Total Quality Management Process. A Systematic Approach, Carfax Publishing Company, Oxfordshire.

[25] KEDAR, A. P., LAKHE, R. R., DESHPANDE, V. S., WASHIMKAR, P. V. \& WAKHARE, M. V. (2008) A comparative review of TQM, TPM and related organisational performance improvement.

[26] Kroslid, D. (1999) In Search of Quality Management. Rethinking and Reinterpreting, Doctoral Thesis, Division of Quality Technology and Management, Linköping University.

[27] Lundquist, R. (1995), Quality Related Costs in Higher Education - A Tool for Improvements?, Research Report 1995:4, Divison of Quality Technology \& Statistics, Luleâ University (in Swedish).

[28] Magnusson, K., Kroslid, D. and Bergman, B. (2003) Six Sigma. The Pragmatic Approach, 2nd ed., Studentlitteratur, Lund.

[29] Martinez-Lorente, A.R., Dewhurst, F. and Dale, G.B. (1998) 'Total Quality Management: origins and evolution of the term', The TQM Magazine, Vol. 10, No. 5, pp.378-386.

[30] NÄSLUND, D. (2008) Lean, six sigma and lean sigma: fads or real process improvement methods? Business Process Management, Vol. 14, 269-287.

[31] Oakland, J. S. (2001) Total Organizational Excellence: Achieving world-class performance, Oxford : ButterworthHeinemann

[32] Pyzdek, T., The Six Sigma Handbook: A Complete Guide for Greenbelts, Blackbelts, \& Managers at All Levels. New York, McGraw-Hill, Inc., 2001.

[33] Sangeeta Sahney, Banwet D.K \& Karunes S., (2004), "Conceptualizing Total Quality Management in Higher Education”, The TQM magazine, Vol. 16(2),203-215.

[34] Sila, I. and Ebrahimpour, M. (2002) 'An investigation of the Total Quality Management survey based on research between 1998 and 2002', International Journal of Quality and Reliability Management, Vol. 19, No. 7, pp.902-970.

[35] Snee, R.D. (2004) 'Six Sigma: the evolution of 100 years of business improvement methodology', International Journal of Six Sigma and Competitive Advantage, Vol. 1, No. 1, pp.4-20. Student (1908) 'The probable error of a mean', Biometrica, Vol. 6, pp.1-25.
[36] Surya Rao. U, and Pal Pandi A. (2006), "Quality Assurance in Technical Institutions", International Journal of Quality and Productivity Management, USA, Vol.06 (01), 40-48.

[37] Surya Rao, U., Pal Pandi A. and Jeyathilagar .D, (2007), "An Analytical Study of Integrated Total Quality Management practices in Technical Education - Faculty Perspective", Proceedings of the 9th International Symposium on Measurement and Quality Control, IIT Madras, India, 375-379.

[38] Tobin, L.M. (1990) 'The new quality landscape: Total Quality Management', Journal of System Management, Vol. 12, No. 3, pp.343-363.

\section{ABOUT THE AUTHORS}

Rallabandi Srinivasu Received his M.Sc Degree from Nagarjuna University Campus in 2000, M.Phil degree from Acharya Nagarjuna University, Guntur .in 2009.PGDTQM degree from NIMSME in 2008. He is currently Pursuing Ph.D in Management from Rayalaseema University, India. Currently working as Director-P.G.,ST.MARY'S Group of institutions, Hyderabad, India. His main research interests are Data Mining, Management Information Systems ,TQM and Management.

G. Satyanarayana Reddy Received his MBA Degree from kakatiya University in 1999 ,. He is currently Pursuing Ph.D in Management from Rayalaseema University, India. Currently working as HOD-MBA in CMRIT, Hyderabad, India. His main research interests are Management Information Systems, TQM and Financial Management.

Vuda Sreenivasarao received his M.Tech degree in Computer Science \& Engg from the Satyabama University, in 2007.Currently working as Professor \& Head in the Department of Information Technology(IT) at St.Mary's college of Engineering \& Technology, Hyderabad, India. He is Currently Pursuing the PhD degree in CSIT Department at JNT University, Hyderabad, India. His main research interests are Data Mining, Network Security, and Artificial Intelligence. He has got 10years of teaching experience .He has published 14 research papers in various international journals. He is a life member of various professional societies like MIACSIT, MISTE and MIAENG.

Srikanth Reddy Rikkula Received his M.Sc Degree from Madras University, Chennai in 2006..PGDBM degree from Osmania University, Hyderabad in $2010 \mathrm{He}$ is currently Pursuing Ph.D in Computer Science from Rayalaseema University, India. Currently working as Associate Professor at St.Mary's college of Engineering \& Technology , Hyderabad, India. His main research interests are Data Mining, Management Information Systems, TQM and Networks. 